Chinese Journal of Organic Chemistry

\title{
多取代吡唑合成最新研究进展
}

\author{
王少华 $a, b, c$ \\ 张帮红 ${ }^{c}$ \\ 陈 洁 $a, b$ \\ 郑莹莹 ${ }^{a, b}$
马爱军*,a,b 徐学涛*, ${ }^{*}, b \quad$ Abdullah, M. Asiri ${ }^{d}$
( ${ }^{a}$ 五邑大学生物科技与大健康学院 广东江门 529020)
( ${ }^{b}$ 江门市大健康国际创新研究院 广东江门 529020)
( ${ }^{c}$ 兰州大学药学院 兰州 730000) \\ ( ${ }^{d}$ Faculty of Science, King Abdulaziz University, Jeddah 999088)
}

冯 娜 $a, b$

\begin{abstract}
摘要 吡唑是一类重要的五元含氮杂环化合物, 广泛存在于许多天然产物、生物活性分子和药物分子中, 而且是一类 重要的有机合成中间体. 因此, 近年来吡唑及其衍生物的合成引起了科学家们的极大兴趣, 并得以迅速发展. 对近年 来多取代吡坐的合成新方法进行了综述，以期对相关领域的研究起到一定的辅助与推动作用.

关键词 吡唑; 合成; 研究进展
\end{abstract}

\section{Recent Progress in Synthesis of Polysubstituted Pyrazoles}

\author{
Wang, Shaohua ${ }^{a, b, c} \quad$ Zhang, Banghong $^{c} \quad$ Chen, Jie $^{a, b} \quad$ Zheng, Yingying $^{a, b} \quad$ Feng, Na ${ }^{a, b}$ \\ Ma, Aijun*,a,b Xu, Xuetao*,a,b Abdullah, M. Asiri ${ }^{d}$ \\ ( ${ }^{a}$ School of Biotechnology and Health Sciences, Wuyi University, Jiangmen, Guangdong 529020) \\ ( ${ }^{b}$ International Healthcare Innovation Institute, Jiangmen, Guangdong 529000) \\ ( ${ }^{c}$ School of Pharmacy, Lanzhou University, Lanzhou 730000) \\ ( ${ }^{d}$ Faculty of Science, King Abdulaziz University, Jeddah 999088)
}

\begin{abstract}
Pyrazole, an important class of nitrogen-containing five-member hetrocyclic compounds, widely exists in natural products, bio-active molecules and drugs, and it is also a valuable intermediate in organic synthesis. The synthesis of polysubstituted pyrazoles has attracted much attention and developed rapidly in recent years. Herein, the recent research progress in the construction of polysubstituted pyrazoles is summarized.
\end{abstract}

Keywords pyrazole; synthesis; research process

含氮杂环类结构单元作为基础的杂环, 广泛存在于 天然产物、药物及功能材料中 ${ }^{[1 \sim 5]}$, 对于现代药物化学 和有机化学有着非常重要的作用. 正是由于上述原因, 发展含氮杂环类化合物的高效合成方法一直是有机化 学家和药物化学家们研究的热点 ${ }^{[610]}$. 在众多的含氮杂 环中, 吡唑是重要的成员之一, 作为关键的结构单元, 广泛存在于许多药物和生物活性分子中(图 1), 如具有 止痛 ${ }^{[11]}$ 、退热 ${ }^{[12]}$ 、抗炎 ${ }^{[13]}$ 、抗菌 ${ }^{[14]}$ 和抗高血糖 ${ }^{[15]}$ 等药 用活性分子. 很多已成为市售药品, 具有代表性的有塞 来昔布(celecoxib) ${ }^{[16]}$ 、吗伐烤昔(mavacoxib) ${ }^{[17]}$ 、雷扎沙 班(razaxaban) ${ }^{[18,19]}$ 等(图 1). 随着对吡唑类化合物合成及 其临床应用研究的深入, 近年来科研工作者也发展出很 多含吡唑结构的生物活性分子, 如 p38 激酶抑制剂 ${ }^{[20] 、}$ 大麻素 1 型受体拮抗剂 ${ }^{[21]}$ 、抗 HIV 病毒试剂[22]和细胞 周期检测点激酶抑制剂(CHK1) $)^{[23]}$ 等. 上述研究结果将 推动基于吡唑结构的创新药物的发展. 此外, 吡唑类化 合物除了临床用药外，也因其具有高效、低毒等特点， 被广泛应用于农药领域，如除草剂、杀菌剂和杀虫杀

\footnotetext{
* Corresponding authors. E-mail: maaijun@wyu.edu.cn; xuetaoxu@wyu.edu.cn

Received June 6, 2019; revised September 1, 2019; published online September 5, 2019.

Project supported by the the National Natural Science Foundation of China (Nos. 21472077, 21772071), the Department of Education of Guangdong Province (Nos. 2017KTSCX185, 2017KSYS010, 2016KCXTD005), and the High-level Talent Research Start-up Project of Wuyi University (Nos. 2018AL002, 2018AL003).

国家自然科学基金(Nos. 21472077, 21772071)、广东省教育厅基金(Nos. 2017KTSCX185, 2017KSYS010, 2016KCXTD005)、五邑大学高层次人才科研 启动(Nos. 2018AL002, 2018AL003)资助项目.
} 
<smiles>Cc1ccc(-c2cc(C(F)(F)F)nn2-c2ccc(S(N)(=O)=O)cc2)cc1</smiles>

Celecoxib<smiles>c1ccc(Cc2cn[nH]c2C2CCN(CCc3ccncc3)CC2)cc1</smiles>

anti-HIV agents<smiles>NS(=O)(=O)c1ccc(-n2nc(C(F)(F)F)cc2-c2ccc(F)cc2)cc1</smiles>

Morvacosi<smiles>[R20]c1cc(C(F)(F)F)nn1-c1ccc2onc(N)c2c1</smiles>

Razaxaban<smiles>CN1CCN(c2[nH]nc(-c3ccc(Cl)cc3)c2-c2ccncc2)CC1</smiles>

p38 MAP kinase inhibitors<smiles>CCc1c(C(=O)NC2CCCN2)nn(-c2ccc(Cl)cc2Cl)c1-c1ccc(C2CC2)cc1</smiles>

cannabinoid type-1 receptor antagonists<smiles>Cn1cc(C2CNN3C2=N[C@H](C2CCCNC2)C(Br)=C3N)cn1</smiles><smiles>Cc1nn(C)c(OCC(=O)c2ccccc2)c1C(=O)c1ccc(Cl)c(C)c1Cl</smiles>

Imidone<smiles>COC(=O)N(OC)c1ccccc1COc1ccn(-c2ccc(Cl)cc2)n1</smiles>

Becmin

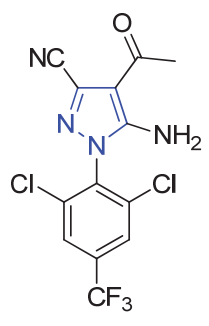

Finney

图 1 一些重要的吡唑化合物

Figure 1 Some important pyrazoles

螨剂. 市场上已经商品化的代表性农药有吡草酮 (benzofenap)、唑菌胺酯(pyraclostrobin)、氟虫腈(fipronil) 等.

鉴于吡唑类化合物极其重要的作用, 发展高效地合 成吡唑的方法一直以来是有机化学以及药学工作者所 关注的热点. 常见的合成策略有: 由 1,3-二羰基化合物 及类似物出发, 通过环化反应获得吡坐, 或者由腙出发 制得吡唑等. 本文介绍了近些年来有关吡唑类化合物的 合成方法, 希望能对本领域的研究起到一定的辅助与推 动作用.

\section{1 由 1,3-二羰基化合物及类似物合成吡唑}

1,3-二羰基化合物和肼类化合物环化是一种沿用至 今的合成吡唑类化合物的重要合成方法. 1,3-亲电性化 合物包括 1,3-二羰基化合物、 $\alpha, \beta$-不饱和羰基化合物以 及 $\beta$-位上带有离去基团的 $\alpha, \beta$-不饱和羰基化合物.

1883 年, Knorr ${ }^{[24]}$ 报道了取代的 1,3-二羰基化合物和 肼反应生成 $1,3,5$-三取代的吡唑. 该反应由于区域选择 性不好, 会生成两种取代基位置不同的异构体 1 和 2 (Eq. 1).

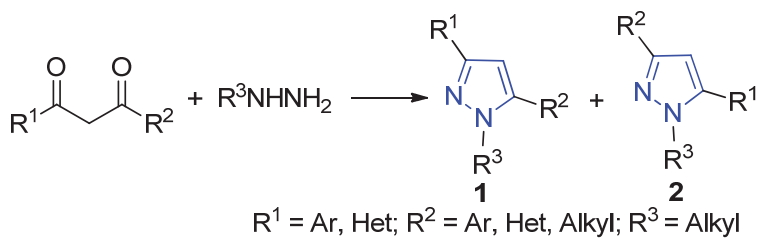

2000 年, Elguero 等 ${ }^{[25]}$ 提出了不同取代基的 1,3-二羰
基化合物与肼类化合物反应合成吡唑的通用反应机理. 取代的肼上两个氮原子都可能与 1,3-二羰基化合物的 1,3-位发生反应，该过程类似羟醛缩合反应，可逆地生 成两种取代基位置不同的异构体，然后再不可逆地脱除 一分子水, 最终得到取代基位置不同的吡唑类化合物 1 和 2 (Scheme 1).

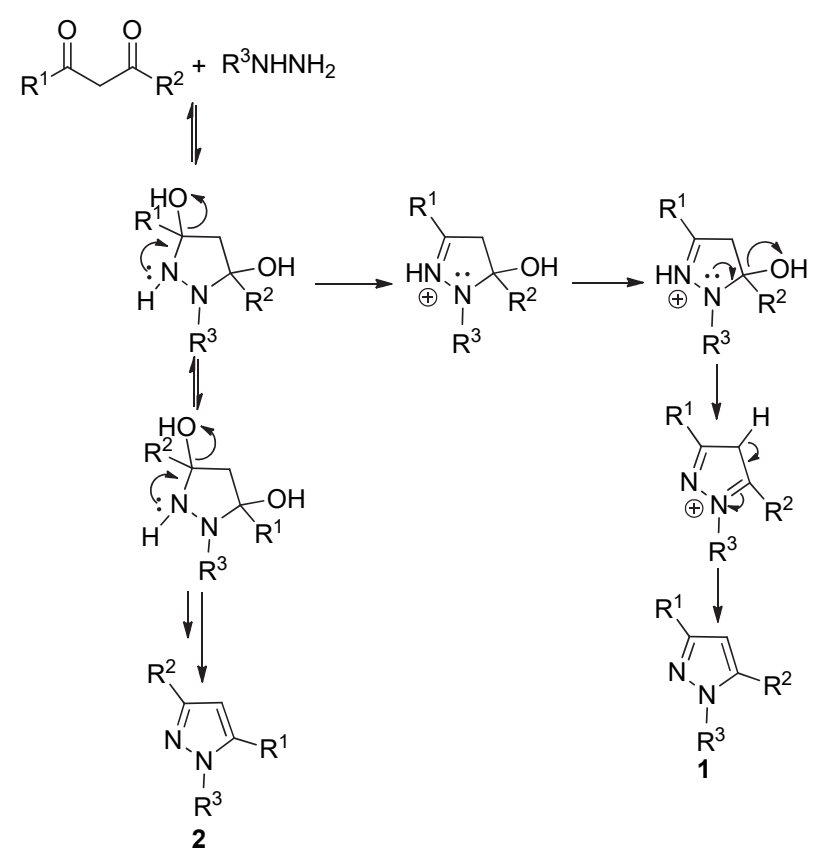

图式 $1 \quad 1,3$-二羰基化合物与肼合成吡唑的机理

Scheme 1 Plausible mechanism for synthesis of pyrazole with 1.3-diketone and hydrazine

2015 年, Alves 课题组 ${ }^{[26]}$ 报道了在路易斯酸作用下 
“一锅法” 反应合成含硒多取代吡唑的合成方法. 以 $1,3-$ 二羰基类化合物、苯肼、取代的二硒醚为原料, $\mathrm{CuBr}$ 为 催化剂, 2,2'-联吡啶(bpy)为配体, 空气条件下在二甲基 亚砜(DMSO)中加热至 $100{ }^{\circ} \mathrm{C}$, 最终以 $98 \%$ 的收率成功 地构建了 C-4 位碳硒键的吡唑化合物 3 (Eq. 2). 该反应 底物适用范围广, 产率良好。

$$
\begin{aligned}
& \begin{aligned}
\mathrm{R}^{1} & \stackrel{\mathrm{CuBr}(10 \mathrm{~mol} \%)}{\mathrm{bpy}(10 \mathrm{~mol} \%)} \\
\mathrm{R}^{1}=\mathrm{Ar} \text {, Alkyl; } \mathrm{R}^{2}=\mathrm{Ar} \text {, Alkyl; } \mathrm{R}^{3}=\mathrm{Ar} \text {, Alkyl } & \begin{array}{c}
\mathrm{DMSO}, 100{ }^{\circ} \mathrm{C} \\
\text { air }
\end{array}
\end{aligned} \\
& \underbrace{\mathrm{N}}_{\mathrm{R}_{3}^{2}} \mathrm{SeR}^{\mathrm{R}^{1}}
\end{aligned}
$$

2016 年, Kivrak 课题组 ${ }^{[27]}$ 对上述方法进行了改进. 首先使用 $\alpha, \beta$-不饱和醛 4 和苯肼反应生成 $\alpha, \beta$-不饱和腙, 然后在碱的作用下和苯硒氯进行环化反应, 以较高的收 率合成 4-苯硒吡唑 5 (Eq. 3).

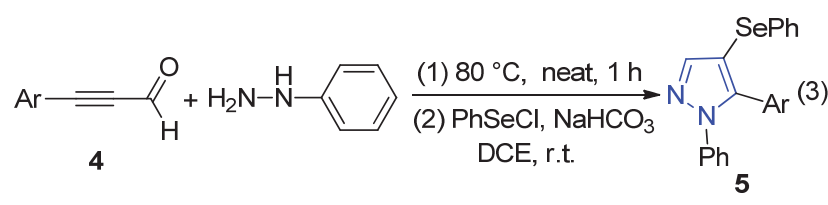

2017 年, 王华课题组 ${ }^{[28]}$ 报道了 “一锅法” 反应合成 含硫多取代吡唑的方法, 该反应以乙酰乙酸乙酯、苯肼、 对甲基苯硫醇为原料, 在 $\mathrm{I}_{2}$ 的催化下, DMSO 作氧化剂, 加热反应至 $70{ }^{\circ} \mathrm{C}$, 最终以 $56 \% \sim 84 \%$ 的收率得到 C-4 含硫的多取代吡唑 6 (Eq. 4). 该方法无需金属催化剂和 溶剂, 且具有良好的选择性.

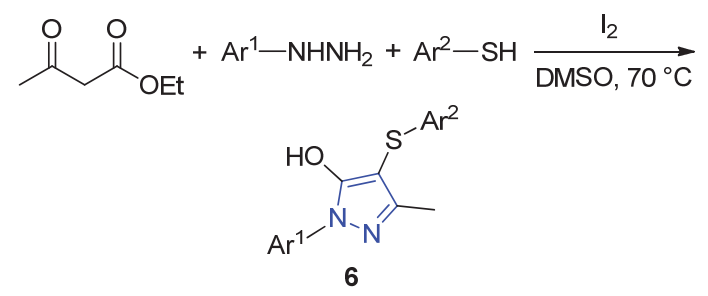

2017 年, Deka 等 ${ }^{[29]}$ 报道了 “一锅多组分反应” 合成 吡唑的方法. 该方法以乙酰乙酸乙酯和水合肼为底物, 先在室温下反应 $2 \min$ 生成中间体 7, 然后再和醛(或者 酮)在 $\mathrm{K}_{2} \mathrm{CO}_{3}$ 为催化剂、水为溶剂的条件下回流 $2 \mathrm{~h}$, 以 $85 \%$ 的收率得到 3,4,5-取代的吡唑 8 (Scheme 2). 该方法 以廉价易得的 $\mathrm{K}_{2} \mathrm{CO}_{3}$ 为催化剂和水作为反应溶剂, 底物 范围广、产量高、操作简单、产物易于分离.

2016 年, 王保民课题组 ${ }^{[30]}$ 发展了碘催化下, 乙醇作 溶剂, 以 $\alpha, \beta$-不饱和羰基化合物 9 和对甲苯磺酰肼为底

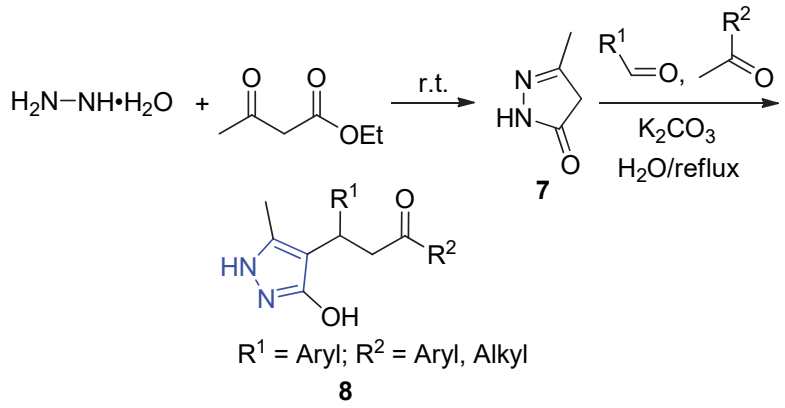

图式 2 一锅多组分反应合成吡唑

Scheme 2 One-pot multi-component reaction for synthesis of pyrazole

物, $75{ }^{\circ} \mathrm{C}$ 反应 $2 \mathrm{~h}$ 生成 3,5-二取代的吡唑 10 的方法(Eq. 5). 该方法简单，条件温和，反应时间短，底物范围广， 产率高.

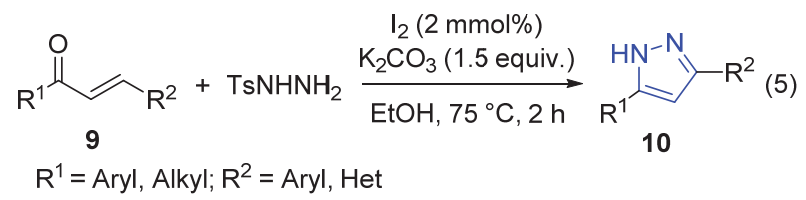

上述反应的可能机理见 Scheme 3 所示. 首先, 在碘 的催化下， $\alpha, \beta$-不饱和酮和对甲苯磺酰肼反应生成 $\alpha, \beta$ 不饱和腙, 再在 $\mathrm{K}_{2} \mathrm{CO}_{3}$ 和碘的作用下, 失去一分子 $\mathrm{HI}$, 得到中间体 11. 之后 $\mathrm{HI}$ 和 $\mathrm{C}=\mathrm{C}$ 进行加成, 生成中间体 12, 随后进行分子内的环化得到 4,5-二氢- $1 H$-吡唑 13 . 碱性条件下，脱去对甲苯磺酰基，从而得到 3,5-二取代 吡唑 10
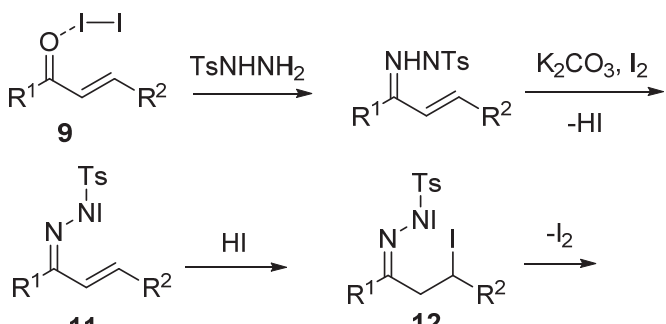

12<smiles>[R]C1=NN([13CH3])C([R1])C1</smiles><smiles>[R]C1=CC([R])NN1[3H]</smiles>

图式 $3 \alpha, \beta$-不饱和酮和对甲苯磺酰肼合成吡唑的机理 Scheme3 Plausible mechanism for the synthesis of pyrazole with unsaturated ketones and $\mathrm{TsNHNH}_{2}$

2015 年, Markovic 和 Joksovic ${ }^{[31]}$ 报道了以水作为溶 剂, 用氨基脲盐酸盐代替肼，与底物 14 发生反应，经过 回流 $2 \mathrm{~h}$ 制得 5-取代-3-羧酸酯吡唑 15 (Eq. 6). 该方法绿 色，条件温和，产率高，并且产物易于分离. 


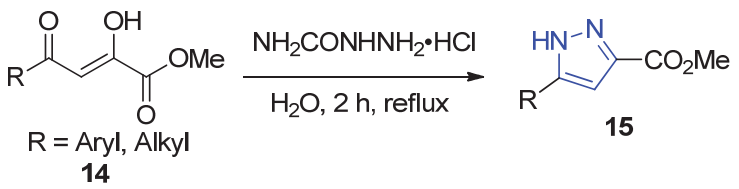

该反应的可能机理为: 第一步, 氨基脲和质子化的 酯 16 进行亲核加成反应, 得到亚胺中间体 17 , 再经分 子内环化脱水, 得到环状缩合的吡唑-1-酰胺衍生物 18 , 然后经质子化得到中间体 19. 在酸性条件下, 水亲核进 攻 19 生成中间体 20 . 由于中间体 20 不稳定, 分解得到 5-取代-3-羧酸酯吡唑 15 和质子化的氨基甲酸 21. 未取 代的氨基甲酸不稳定，在质子作用下，氮原子发生质子 化生成阳离子, 随后分解生成氨基阳离子和 $\mathrm{CO}_{2}$ (Scheme 4).<smiles>[R]C(=O)C=C(O)C(=O)OCC</smiles><smiles>[R]C(=O)C=C(O)C(=O)OCC</smiles><smiles>[R]C(=O)CC(=NNC(N)=O)C(=O)OCC</smiles><smiles>[R]c1cc(C(=O)OCC)nn1CCC(C)C</smiles>

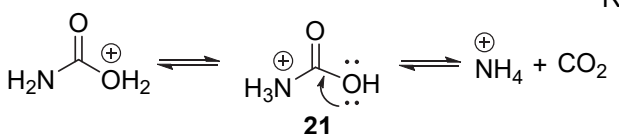
15

图式 4 氨基腿盐酸盐合成 3,5-二取代吡唑的机理 Scheme 4 Plausible mechanism for synthesis of 3,5-disubstituted pyrazoles with semicarbazide hydrochloride

二氧化硫嫝(TUD) 是便宜易得的有机催化剂，反应 完成后, 通过过滤分离产物, 剩余的 TUD 水溶液可以重 复使用数次, 其催化活性不会减弱. 2016 年, Vekariya 课 题组 ${ }^{[32]}$ 报道了使用 TUD 作催化剂, 以乙酰乙酸乙酯、 水合肼、苯甲醛和丙二腈为底物, “一锅法” 四组分反 应制得 1,4-二氢吡喃并 [2,3-c]吡唑-5-甲腈衍生物 22 (Scheme 5). 该方法产率高, 后处理过程简单, 避免使 用有机溶剂，反应时间短，催化剂可重复使用.

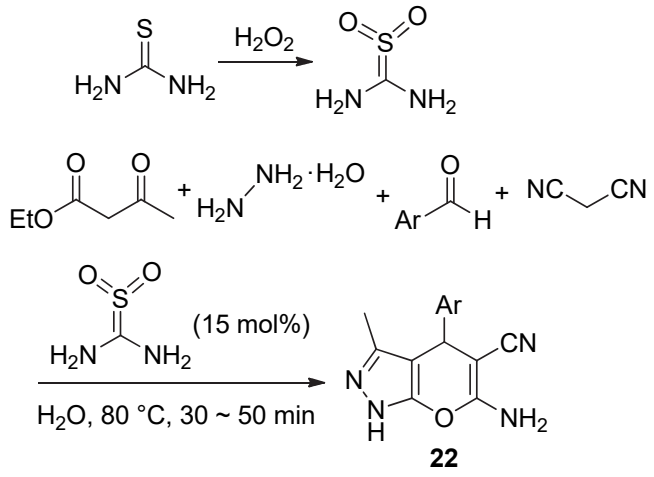

图式 5 乙酰乙酸乙酯、水合肼、苯甲醛和丙二腈多组分反应 合成吡唑

Scheme 5 Synthesis of pyrazoles from ethyl acetoacetate, hydrazine hydrate, benzaldehyde and malononitrile

同年, Banerjee 小组 ${ }^{[33]}$ 报道了使用 $\mathrm{ZrO}_{2}$ 纳米颗粒催 化的 “一锅法” 四组分反应合成吡喃并 $[2,3-c]$ 吡唑衍生 物 23 (Eq. 7). 该反应以乙酰乙酸乙酯、肼、芳香甲醛、 丙二腈为底物, $\mathrm{ZrO}_{2}$ 纳米颗粒作为催化剂, EtOH- $\mathrm{H}_{2} \mathrm{O}$ 为 溶剂，在室温下反应 $5 \mathrm{~min}$, 以 $95 \%$ 的收率得到单一产 物 23. 该反应实验操作简单、反应快、产率高、产物可 直接从乙醇中重结晶获得, 避免了使用柱色谱进行分离 纯化. $\mathrm{ZrO}_{2} \mathrm{NPs}$ 催化剂既无毒又可重复使用，是一种绿 色高效合成吡唑环的方法.

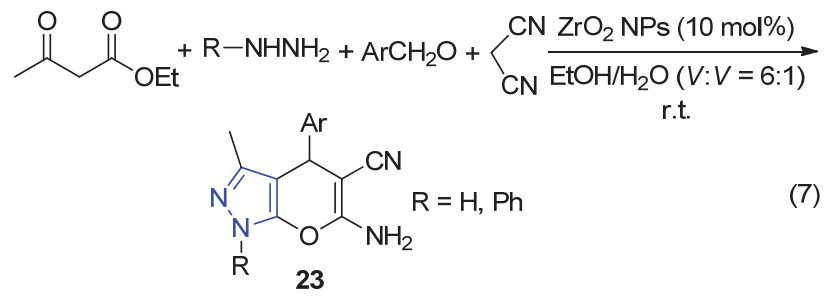

\section{2 由腙及其类似物合成吡唑}

2014 年, 王晓龙小组 ${ }^{[34]}$ 在干燥的二氯甲烷中加入 卤代的腙、 $\beta$-酮磷酸酯 24 和 2 equiv.的氢氧化锂, 室温 条件下反应 $10 \mathrm{~h}$ 得到 $1,3,5$-三取代吡坐 25 (Eq. 8). 该反 应必须在无水条件下才能实现. 对底物的范围和官能团 兼容性研究发现，当腙苯环上 $\mathrm{R}^{1}$ 为缺电子取代基时，反 应收率不受影响; 当 $\beta$-酮磷酸酯 24 上的 $\mathrm{R}^{3}$ 取代基为吸 电子基团，如酯基、氨基、酮、三氟甲基等时，都能以 较好的收率(55\% 95\%) 合成相应的 3-位取代的吡唑. 该方法原料易得，在室温条件下就能反应，区域选择性 高，底物范围广，产率高.

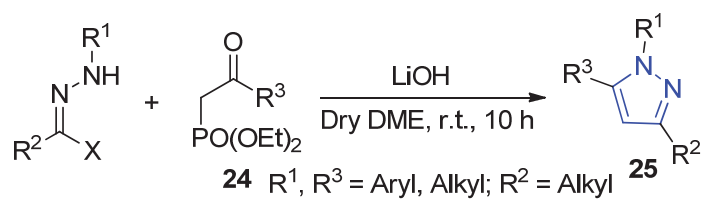


2014 年, 唐萌课题组 ${ }^{[35]}$ 在碱的作用下, $N$-烷基对甲 苯磺酰腙和末端炔烃反应得到了 $1,3,5$-三取代的吡唑 26, 随后该课题组 ${ }^{[36]}$ 对之前方法进行改进, 使用 $\mathrm{AlCl}_{3}$ 催化 $N$-烷基对甲苯磺酰腙和末端炔烃合成 1,3,5-三取代 的吡唑 27 (Scheme 6). 该方法反应条件温和, 在室温条 件下就能进行反应.

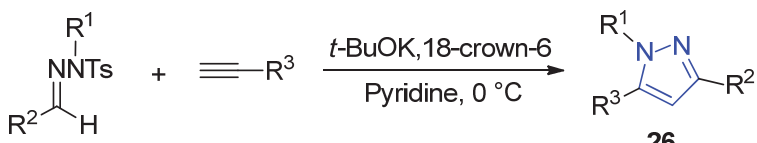

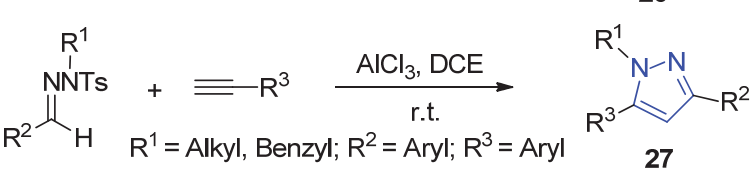

图式 $6 N$-烷基对甲苯磺酰腙和末端炔烃合成吡唑 Scheme 6 Synthesis of pyrazoles from $N$-alkyl- $p$-toluenesulfonylhydrazone and terminal alkyne

可能的机理见 Scheme 7 所示. 炔基钾和 $N$-烷基对<smiles>[R]C#CC([R])=NN[R]([R])[H]</smiles>

图式 $7 N$-烷基对甲苯磺酰腙和末端炔烃合成 1,3,5-三取代吡 唑的机理

Scheme 7 Plausible mechanism for the synthesis of 1,3,5-trisubstituted pyrazoles with $N$-alkylated tosylhyrazones and terminal alkynes
甲苯磺酰腙进行亲核加成, 失去一分子对甲苯磺酰基阴 离子生成中间体 28 , 然后经 1,3-氢转移失去一个质子, 最后经分子内环化再获得一个质子, 得到 1,3,5-三取代 的吡唑 26. 该方法可以进行克级规模制备 1,3,5-取代的 吡唑类化合物, 并且底物适用范围广, 区域选择性好, 产率高.

2015 年, Wang 课题组 ${ }^{[37]}$ 报道了 $\mathrm{I}_{2}$-叔丁基过氧化氢 (TBHP)催化的 $N$-磺酰腙和取代异氧 29 合成 5-氨基吡唑 类化合物 30 (Eq. 9). 该方法不需要金属催化，底物适用 性范围广，原子利用率高，反应时间短，产率高.

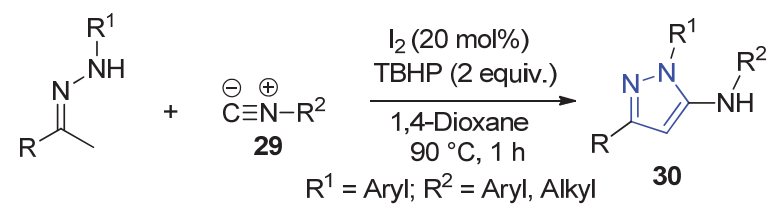

作者推测反应机理为: 在 $\mathrm{I}_{2}$ 催化下, $N$-磺酰腙先转 化为 $\alpha$-碘取代的腙 31, 随后失去 HI 得到偶氮烯烃 32, 异氰和偶氮烯烃进行共轭加成生成中间体 33 , 最后进 行分子内环化和 1,3-氢转移合成得到 5-氨基吡唑类化合 物 (Scheme 8).

2016 年, Alizadeh 课题组 ${ }^{[38]}$ 使用乙醇作溶剂, 先将 氯代的腙和 $\mathrm{Et}_{3} \mathrm{~N}$ 的混合物在室温下搅拌 $10 \mathrm{~min}$, 然后 将 3-甲酰基色酮 34 加入到反应体系中，并将反应物搅 拌 $4 \mathrm{~h}$, 高产率地得到化合物 35 (Eq. 10). 该课题组研究 了当 $\mathrm{X}$ 为 $\mathrm{H} 、 \mathrm{Cl} 、 \mathrm{Me} ; \mathrm{Ar}$ 为 $\mathrm{Ph} 、 4-\mathrm{ClC}_{6} \mathrm{H}_{4}$ 等 5 种取代 基的反应情况，都能以 $82 \% \sim 86 \%$ 的良好收率得到产物. 该反应优点：区域选择性高，实验操作简单，产物收率 高，易于纯化和反应条件温和.

2016 年, 黄国生课题组 ${ }^{[39]}$ 报道了铜催化的腙和硝 基烯的[3+2]反应，合成了 1,3,4-三取代和 1,3,4,5-四取

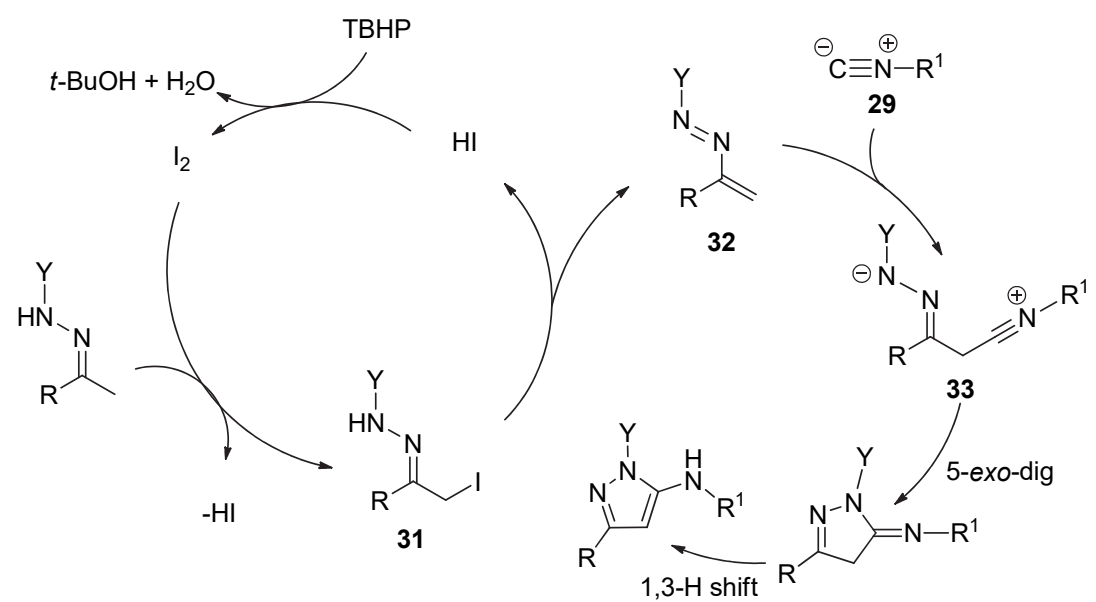

图式 $8 N$-磺酰腙和取代异氰合成 5-氨基吡唑的机理

Scheme 8 Plausible mechanism for the synthesis of 5-aminopyrazoles with $N$-sulfonyl hydrazones and isocyanides 


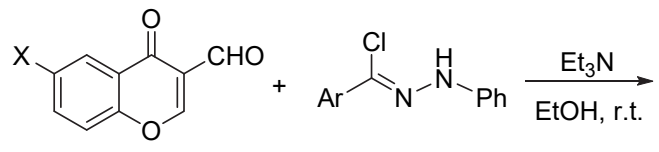

34<smiles>[X]c1ccc(O)c(C(=O)c2cc([Al])nn2-c2ccccc2)c1</smiles>

代吡唑 36 (Eq. 11).

$$
\mathrm{R}^{1}=\mathrm{Aryl} ; \mathrm{R}^{2}=\mathrm{Alkyl} \underset{\substack{1,4 \text {-dioxane, } 100{ }^{\circ} \mathrm{C} \\ \text { air, } 9 \mathrm{~h}}}{\stackrel{\mathrm{CuCl}(20 \text { mol\%) }}{\mathrm{Na}^{1-\mathrm{N}}-\mathrm{CO}_{3} \text { (1 equiv.) }}}
$$<smiles>[R2]c1nn([R1])cc1-c1ccccc1</smiles>

该反应机理如 Scheme 9 所示. 首先腙在碱的作用 下失去质子, 再和硝基烯进行 Michael 加成得到中间体 37 , 随后进行分子内环化, 脱去一分子亚硝酸得到中间 体 38, 然后经二价铜氧化, 获得一个质子生成 $1,3,4,5-$ 四取代吡唑(Scheme 9). 该反应原料易得, 底物适用范 围广，产率较好。

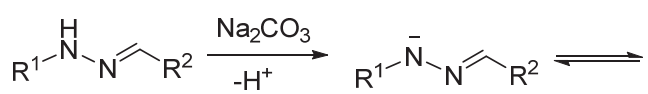<smiles>[R]CN=N[R]([R])=C([R])[N+](=O)[O-]</smiles><smiles>[R1]C1=C([R])N([R1])[N-]C1[R]</smiles>

图式 9 腙和硝基烯合成 1,3,4-三取代和 1,3,4,5-四取代吡唑的 机理

Figure 9 Plausible mechanism for the synthesis of 1,3,4-trisubstituted and 1,3,4,5-tetrasubstituted pyrazoles with hydrazones and nitroolefins

2016 年, 江焕峰课题组 ${ }^{[40]}$ 报道了一种更加绿色的 合成吡唑的方法, 即使用对甲苯磺酰腙和碳化钙为底 物, 在碱和水为溶剂条件下合成 3,5-二取代吡唑 39 (Eq. 12). 该反应不需要金属催化剂, 产率良好, 并且可以用 于工业生产，但区域选择性不好.

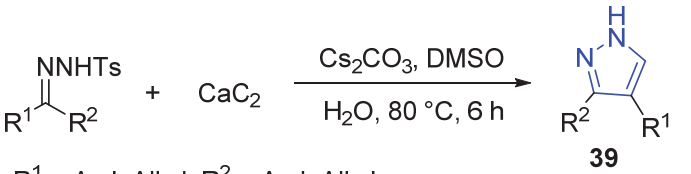

$\mathrm{R}^{1}=$ Aryl, Alkyl; $\mathrm{R}^{2}=$ Aryl, Alkyl

作者推测在 $\mathrm{Cs}_{2} \mathrm{CO}_{3}$ 作用下，对甲苯磺酰腙去质子 化得到铯盐 40. 该反应机理有两种可能路径(Scheme 10). 一条可能路径是, 在加热条件下, 铯盐 40 先生成 重氮化合物, 然后和 $\left[\mathrm{D}_{2}\right]$-乙炔气体 $[3+2]$ 环化生成 $3 H$ 吡唑化合物 $\mathbf{4 2}$; 另一条可能路径是: 铯盐 40 的氮负阴 离子和 $\left[\mathrm{D}_{2}\right]$-乙炔气体进行亲核加成反应，生成碳负离子 中间体 41, 分子内的碳负离子进行亲和进攻，随后对甲 苯磺酰基阴离子和铯离子结合离去, 得到 $3 H$-吡唑化合 物 42. 当 $R^{1}=H$ 时，分子内氢经过 $[1,5]$ 氢转移和异构化 得到产物. 当 $\mathrm{R}^{1} \neq \mathrm{H}$ 是富电子基团时，先形成转移状态 43, $\mathrm{R}^{1}$ 进行 $\mathrm{C} 4$ 位迁移, 随后进行 1,5- $\sigma$ 键转移生成产物.

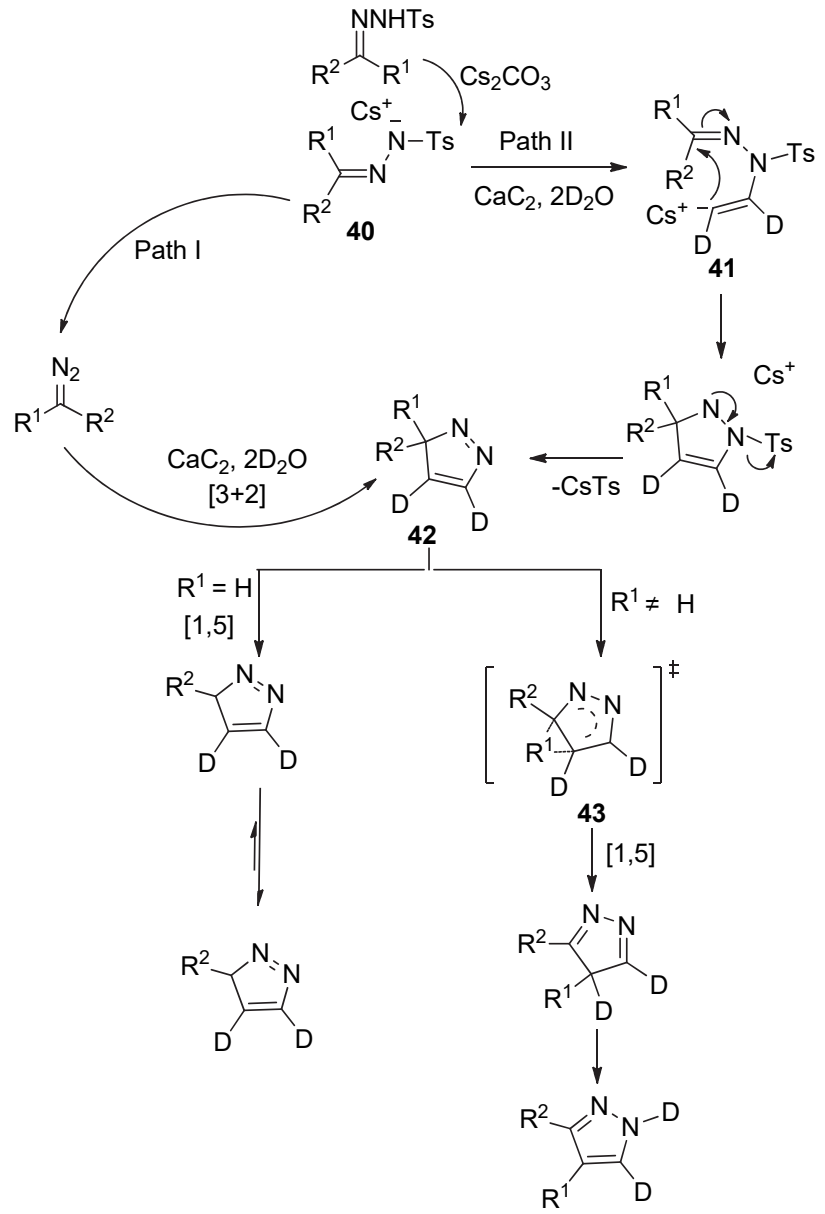

图式 10 对甲苯磺酰腙和碳化钙合成 3,5-二取代吡唑的机理 Scheme 10 Plausible mechanism for synthesis of 3,5-disubstituted pyrazoles with tosylhyrazones and calcium carbide

同年, Pramanik 课题组 ${ }^{[41]}$ 也报道了一种绿色合成吡 唑类化合物的方法, 用磁性可分离的 $\mathrm{Fe}_{3} \mathrm{O}_{4} @ \mathrm{SiO}_{2}-\mathrm{SO}_{3} \mathrm{H}$ 
纳米粒子，高效地合成了吡唑稠合的异香豆素类化合物 (Eq. 13). 该反应无需溶剂, 以 44 和芳基腙为底物, 使用 磁性可分离的 $\mathrm{Fe}_{3} \mathrm{O}_{4} @ \mathrm{SiO}_{2} \mathrm{SO}_{3} \mathrm{H}$ 纳米颗粒固体酸作为催 化剂, 以良好的收率合成吡唑稠合的异香豆素类化合物 45. 此反应无需使用溶剂, 底物适用范围, 催化剂可以 分离和回收.

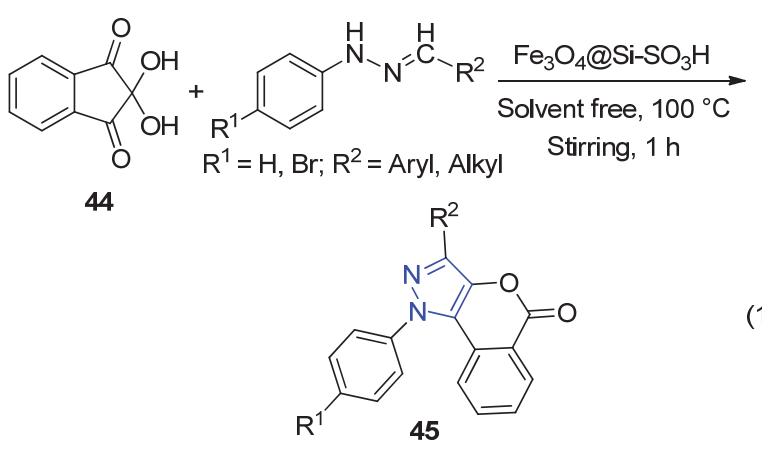

\section{3 由叠氮或重氮反应合成吡唑}

2013 年, 俞永平课题组 ${ }^{[42]}$ 报道了使用乙烯基叠氮 46, 醛和对甲苯磺酰肼, “一锅法” 多组分合成了 $3,4,5-$ 三取代吡唑 47 (Eq. 14). 该方法底物适用范围广、产率 高.

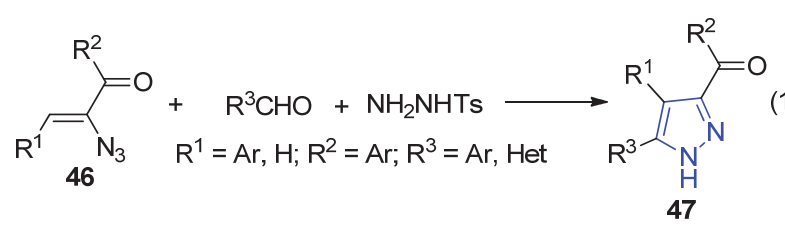

上述反应的可能机理为: 醛和对甲苯磺酰肼缩合生 成对甲苯磺酰腙, 随后在碱性和加热条件下生成重氮化 合物, 重氮化合物和乙烯基叠氮 46 发生 $[3+2]$ 环化反应 得到中间体 48, 48 失去叠氮酸后再进行异构化得到产物 (Scheme 11).

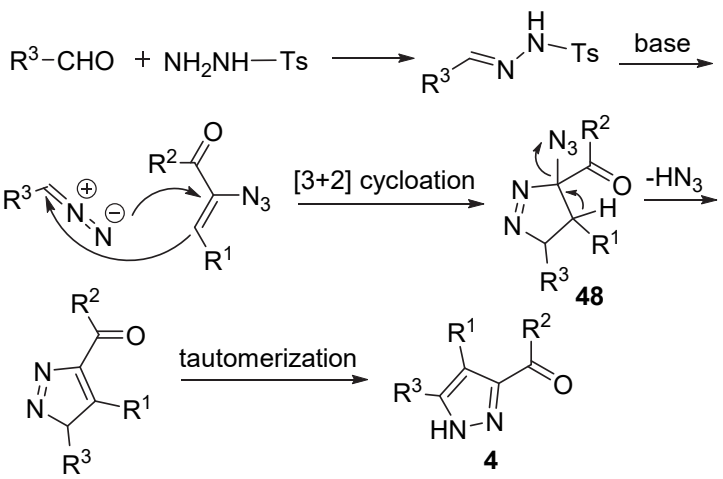

图式 11 乙烯基叠氮、醛和对甲苯磺酰肼合成 3,4,5-三取代吡 唑的机理

Scheme 11 Plausible mechanism of 3,4,5-trisubstituted $1 H$ pyrazoles with vinyl azide, aldehyde, and tosylhydrazine
2017 年，胡跃飞课题组 ${ }^{[43]}$ 报道了一种四步串联反 应合成吡唑类化合物的方法，1,3-二芳基-1,3-二酮、 $\mathrm{TsN}_{3}$ 、甲胺水溶液、 $\mathrm{Na}_{2} \mathrm{CO}_{3}$ 在 $N, N$-二甲基甲酰胺(DMF) 溶液加热至 $85{ }^{\circ} \mathrm{C}$, 反应 $3 \mathrm{~h}$ 后得到成 3,5-二芳酰基-4芳基吡唑 49 (Eq. 15).

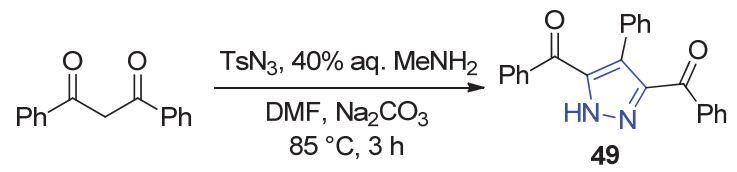

该反应首先在甲胺的作用下，1,3-二芳基-1,3-二酮 和对甲苯磺酰基叠氮反应生成重氮化合物 $\mathbf{5 0}$, 随后在 甲胺的作用下进行 $\mathrm{C}-\mathrm{C}$ 键断裂, 得到重氮化合物 51 . 51 与 1,3-二芳基-1,3-二酮在碱的作用下得到的烯醇化合 物 52 进行 1,3-偶极环加成反应, 最终得到吡唑产物 3,5二芳酰基-4-芳基吡唑 49 (Scheme 12).

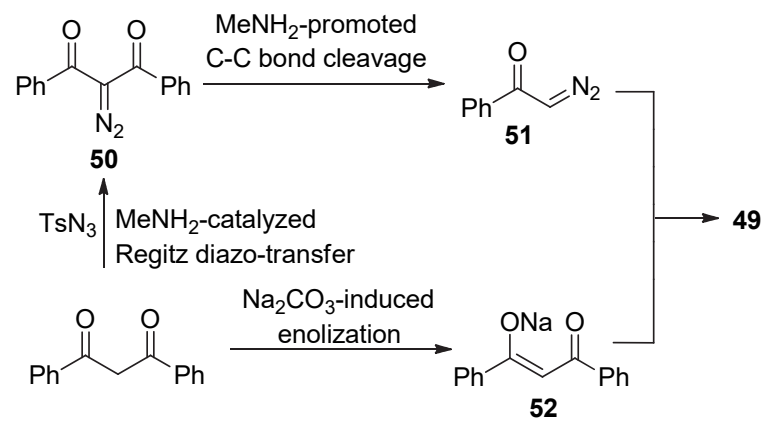

图式 12 串联合成 3,5-二芳酰基-4-芳基吡唑的反应途径 Scheme 12 Plausible pathway for the tandem synthesis of 3,5diaroyl-4-arylpyrazoles

2014 年, Namboothiri 课题组 ${ }^{[44]}$ 报道, 在搅拌下, $\alpha$ 重氮基- $\beta$-酮砜(54)首先生成重氮甲基砜阴离子，再和乙 烯砜 55 进行 1,3-偶极环加成, 然后在碱性条件下选择性 地消除苯磺酰基，最后得到产物 55 (Eq. 16). 该方法反 应条件温和，底物适用范围广，产率高.

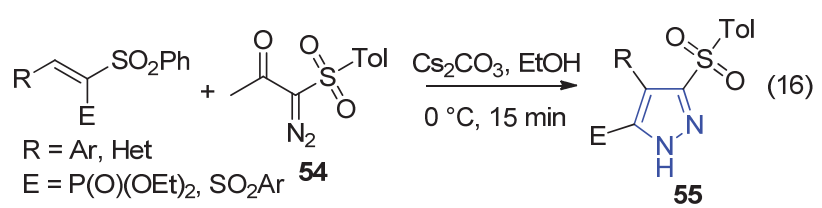

53

2016 年, 该课题组 ${ }^{[45]}$ 也报道了由查尔酮和 $\alpha$-重氮 基- $\beta$-酩酯区域选择性地合成吡唑酮酯 56 的方法(Eq. 17). 该方法与之前报道的方法类似，尽管产率中等，但 是区域选择性高.

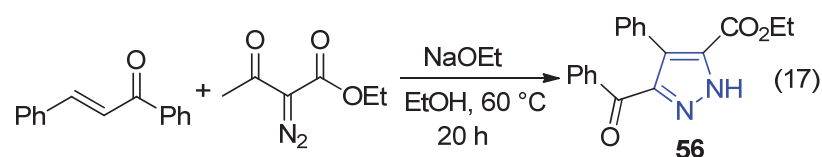


2015 年, Mohanan 课题组 ${ }^{[46]}$ 在碱性条件下, 用 Bestmann-Ohira 试剂(含氧的丙基膦酸酯 57)和 $\alpha, \beta$-不饱 和醛进行反应，合成了乙烯基吡唑 $\mathbf{5 8}$ (Eq. 18).

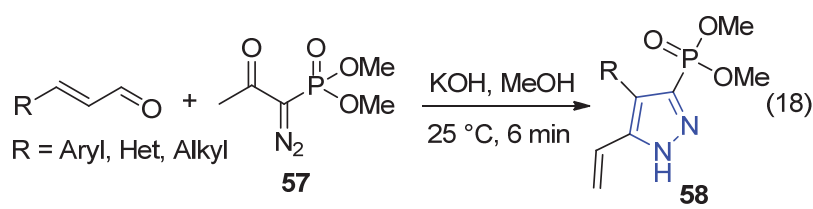

该反应可能机理如 Scheme 13 所示. BOR 在甲醇溶 液中形成重氮甲基阴离子, 再和肉桂醛进行共轭加成、 环化生成中间体 $\mathbf{5 9}$, 然后 $\mathbf{5 9}$ 和另一分子的 BOR 反应生 成二氢化吡唑炔 60 , 随后进行 1,3-氢转移、芳构化生成 乙烯基吡唑. 该方法也可以用于合成磷酰基类的吡唑生 物碱.

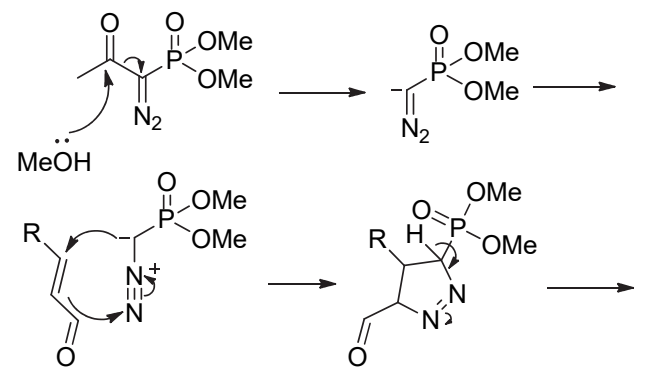

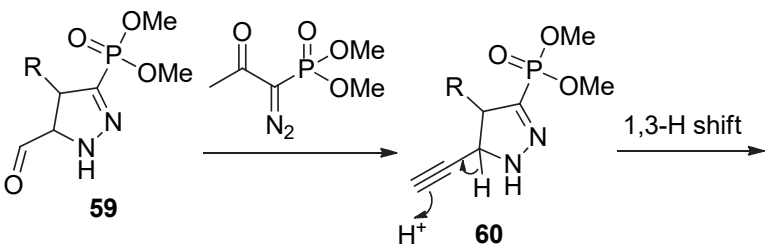<smiles>[R]c1c(P(=O)(OC)OC)n[nH]c1C=C</smiles>

图式 13 Bestmann-Ohira 试剂和 $\alpha, \beta$-不饱和醛合成乙烯基吡 唑的反应机理

Scheme 13 Plausible mechanism for the synthesis of vinylpyrazoles with $\mathrm{BOR}$ and $\alpha, \beta$-unsaturated aldeydes

2016 年, 万小兵课题组 ${ }^{[47]}$ 报道, 在四丁基碘化铵和 TBHP 催化作用下, 烯烃和重氮乙酸乙酯经过 $[3+2]$ 环 化、氧化脱氢过程, 最终得到吡唑产物 61 (Eq. 19). 该反 应原料易得, 原子利用率高, 底物范围广, 反应条件环 保.

$$
\begin{aligned}
& \mathrm{R}^{1}=\mathrm{CO}_{2} \mathrm{R} \\
& \mathrm{R}^{2}=\mathrm{H}, \mathrm{CO}_{2} \mathrm{R}(\mathrm{R}=\text { alkyl })
\end{aligned}
$$

\section{4 其它合成吡唑}

2016 年，严汝龙课题组 ${ }^{[48 a]}$ 报道了一种简单的合成 吡坐 $N$-氧化物的方法. 在四氢呋喃(THF)溶剂中，以 $N$-(3-苯基丙-2-炔-1-基)苯胺(62)和 $\mathrm{AgNO}_{2}$ 为底物, 在 $100{ }^{\circ} \mathrm{C}$ 下反应 $6 \mathrm{~h}$, 以 $85 \%$ 产率得到 1,3 -二苯基- $1 H$-吡唑 $N$-氧化物 63 (Eq. 20). 该反应首次将 $\mathrm{AgNO}_{2}$ 用作合成吡 唑 $N$-氧化物的 $\mathrm{NO}$ 源，含 $N$-炔丙基胺上的各种取代基在 反应中都不受影响, 以较高的收率得到吡唑 $N$-氧化物.

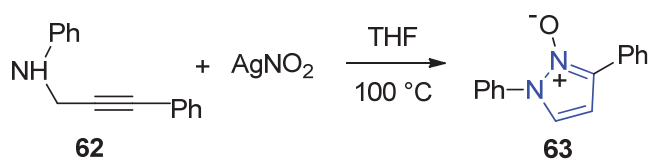

作者推测该反应可能机理为：在高温条件下, Ag$\mathrm{NO}_{2}$ 分解产生硝基自由基. 硝基自由基获得 $N$-(3-苯基 丙-2-炔)-1-苯胺上的氢自由基生成 $\mathrm{HNO}_{2}$ 和含氮自由基 64, 随后 64 与 $\mathrm{HNO}_{2}$ 分解产生的硝基自由基结合，再与 一价的银配位得到中间体 $\mathbf{6 5}$. 在银催化下, 65 分子内环 化生成 66, 再在质子的作用下进行结构互变, 最终生成 吡唑 $N$-氧化物(Scheme 14).

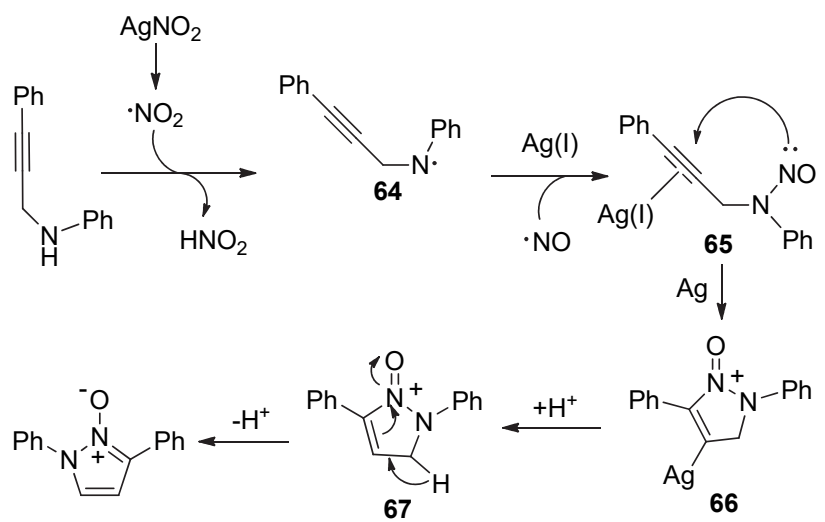

图式 $14 N$-(3-苯基丙-2-炔-1-基)苯胺合成吡唑 $N$-氧化物的反 应机理

Scheme 14 Plausible mechanism for the synthesis of substituted pyrazole $N$-oxides from $N$-propargylamines

同年, Saikia 小组 ${ }^{[48 b]}$ 使用 AgOTf 为催化剂, 在乙酸 和氯仿的混合溶剂中加入炔丙基胺 68 和 3 equiv. 的亚硝 酸钠，在 $0{ }^{\circ} \mathrm{C}$ 缓慢恢复至室温的条件下反应 $3 \mathrm{~h}$, 以 $85 \%$ 的产率得到吡唑 $N$-氧化物 69 (Eq. 21). 该方法产率 高，反应条件温和.

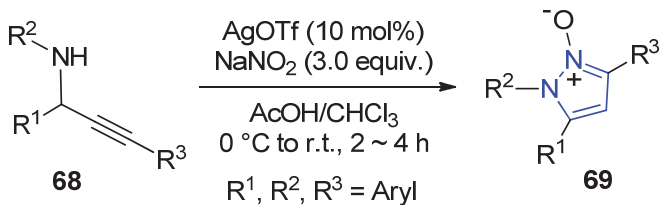




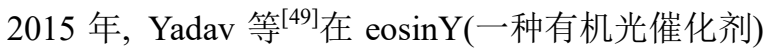
和空气 $\left(\mathrm{O}_{2}\right)$ 作为氧化剂条件下, 以乙醇为溶剂, 以苯甲 醛、丙二腈和苯肼为底物, 于室温下, 使用简单的家用 紧凑型荧光灯 (CFL, $22 \mathrm{~W}$ ) 照射该反应体系, 最终以 95\%收率得到吡唑类化合物 70 (Eq. 22). 该方法无需金 属条件, 原料简单易得, 反应时间短, 后处理简单, 产 物易于分离, 无需柱色谱, 产物产率高.

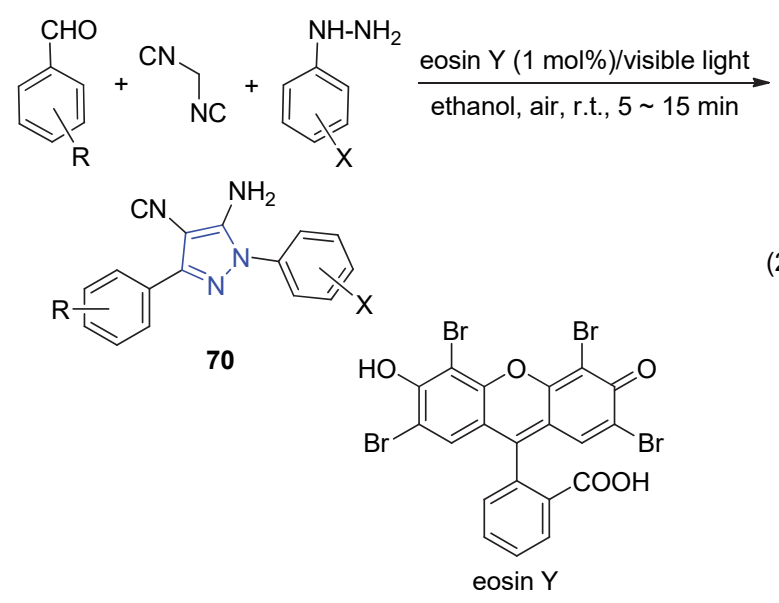

2017 年, 朱成建课题组 ${ }^{[50]}$ 使用腙 71 和 2-澳- 1,3-二 羰基化合物为反应底物, 在可见光催化下, 经过 $[4+1]$ 环化、芳构化合成吡唑衍生物 72 (Scheme 15). 该反应 过程经历了一个连续的偶联/环化/芳构化过程, 反应条 件温和，以高效且经济的方式快速获得吡唑骨架.

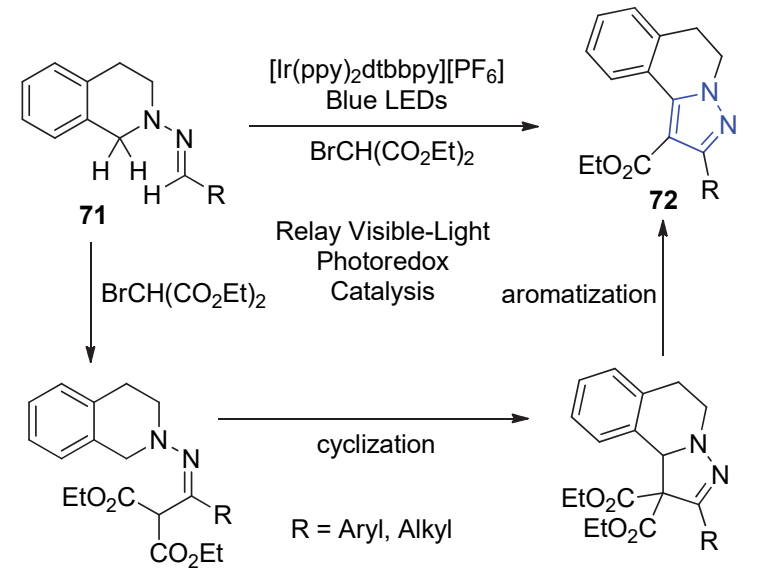

图式 15 2-溴-1,3-二羰基化合物合成吡唑的机理

Scheme 15 Plausible mechanism for the synthesis of pyrazole by 2-bromo-1,3-dicarbonyl compound

2014 年, Dhage 课题组 ${ }^{[51]}$ 报道了一种合成吡唑- 4羧酸酯的新方法, 即用过渡金属 $\operatorname{Pd}($ II) 作为催化剂, $\alpha, \beta$ 炔腙为底物，由配体控制来合成吡唑类化合物 73 或 74 (Eq. 23). 优化反应条件发现, 当催化剂为 $\operatorname{Pd}(\mathrm{TFA})_{2}$, 且 使用配体 $\mathrm{L}_{1}$ 时, 该反应以 $91 \%$ 的收率得到产物 73. 不加 配体, 使用 $\mathrm{DMSO} / \mathrm{MeOH}(V: V=2.5: 3)$ 混合溶剂时,
在室温下反应 $72 \mathrm{~h}$, 没有 73 生成, 仅以优异的产率 $(86 \%)$ 得到化合物 74 . 几种不同底物的 $\alpha, \beta$-炔烃腙都能 以良好的收率得到相应的产物(76\% 98\%). 当以烷基 代替炔末端的芳基时，产物收率相对较低(76\%), 但是 当 $\mathrm{R}^{1}=\mathrm{Me}, \mathrm{R}^{2}=\mathrm{Ph}, \mathrm{Ar}=4-\mathrm{CF}_{3} \mathrm{C}_{6} \mathrm{H}_{4}$ 时，产物的收率达到 98\%.

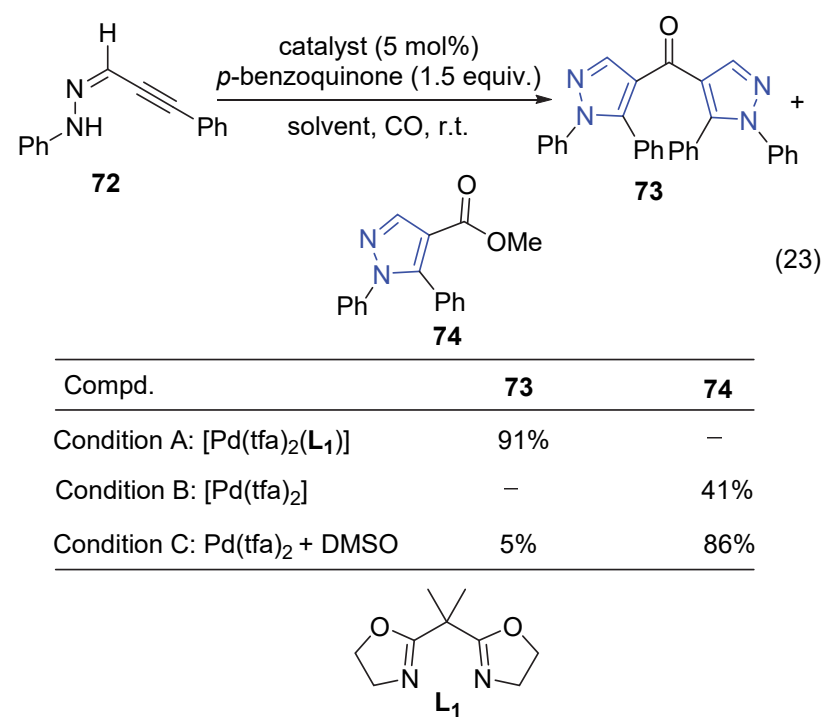

2014 年, 刘培念课题组 ${ }^{[52]}$ 用叮啶铑催化的肼和炔 烃进行加成一环化串联反应合成了四取代吡唑 76 (Scheme 16). 该串联反应通过酰肼的 $\mathrm{C}-\mathrm{N}$ 键和炔烃进 行 $[3+2]$ 环化, 随后酰胺的 $\mathrm{C}-\mathrm{N}$ 键断裂, 再环化脱水. 通过对反应条件的优化篮选，发现在 $\left[\mathrm{Cp} * \mathrm{RhCl}_{2}\right]_{2}(2.5$ mol\%)和 $\mathrm{NaOAc}(25 \mathrm{~mol} \%$ ) 存在下, $\mathrm{MeCN}$ 作溶剂在 $60{ }^{\circ} \mathrm{C}$ 下反应 $5 \mathrm{~h}$, 以最高 $88 \%$ 产率得到单一产物 76. 该 课题组在最优的反应条件下, 探究了这种串联转化的底 物适用范围. 首先当苯环对位取代基 $\mathrm{R}$ 为给电子基团 时，其产率优于苯环对位是吸电子基团的产率. 当邻位 有 $\mathrm{Me}$ 取代时, 产率有所降低, 可能是环化作用时空间

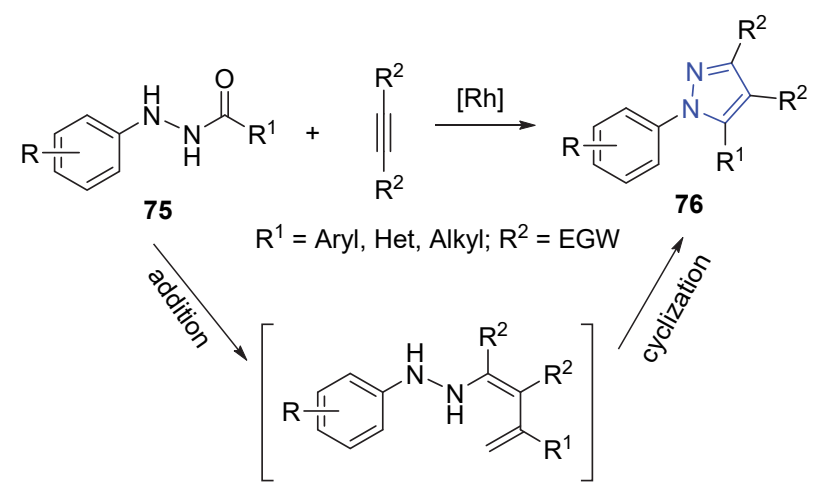

图式 16 肼和炔烃合成四取代吡唑

Scheme 16 Cascade process for synthesis of tetra-substituted pyrazole from hydrazine and alkyne 
位阻的影响所致. 接下来, 将 $\mathrm{R}^{2}$ 变换为不同的芳基取代 基，均可得到预期的产物，产率在 91\% 96\%之间.

2017 年, 赵军锋课题组 ${ }^{[53]}$ 在钯催化下, 芳基肼、末 端取代炔烃和 $\mathrm{CO} /$ 氧气进行 “一锅法” 多组分串联反应, 合成了三取代吡唑 77 (Eq. 24).

$$
\mathrm{Ar}-\mathrm{NHNH}_{2}+\underset{\mathrm{R}=\text { Aryl, Alkyl }}{\equiv} \underset{\mathrm{CO} / \mathrm{O}_{2}}{\stackrel{\mathrm{Pd} \text { cat. }}{\longrightarrow}}
$$

上述反应经过五步的串联反应，包括: $\mathrm{C}-\mathrm{N}$ 断裂、 CO 插入、Sonogashira 偶联、Michael 加成环化(Scheme 17). 该方法区域选择性好、产率高.

2013 年，詹庄平课题组 ${ }^{[54]}$ 报道了路易斯碱作用下 炔丙基腙合成吡唑的方法. 该反应经历分子内环化、 1,3-磺酰基转移，合成了多取代 4-磺酰基- $1 H$-吡唑 79 (Scheme 18).

2017 年, 该课题组 ${ }^{[55]}$ 对此方法进行改进, 使用 $N$ 炔丙基磺酰腙通过 $\mathrm{Pd}(\mathrm{II}) / \mathrm{Cu}(\mathrm{I})$-催化的 Sonogashira/环化 反应, 高效地合成了多取代吡唑(Eq. 25). 上述反应的机 理为: 底物 80 和取代的碘苯通过 Sonogashira 偶联反应 生成化合物 82. 在三乙胺作用下, 82 异构化得到联烯 83. 83 经分子内环化得到中间体 84, 再经两次异构化, 最终生成产物 81 (Scheme 19). 该反应底物适用范围广、 产率高。

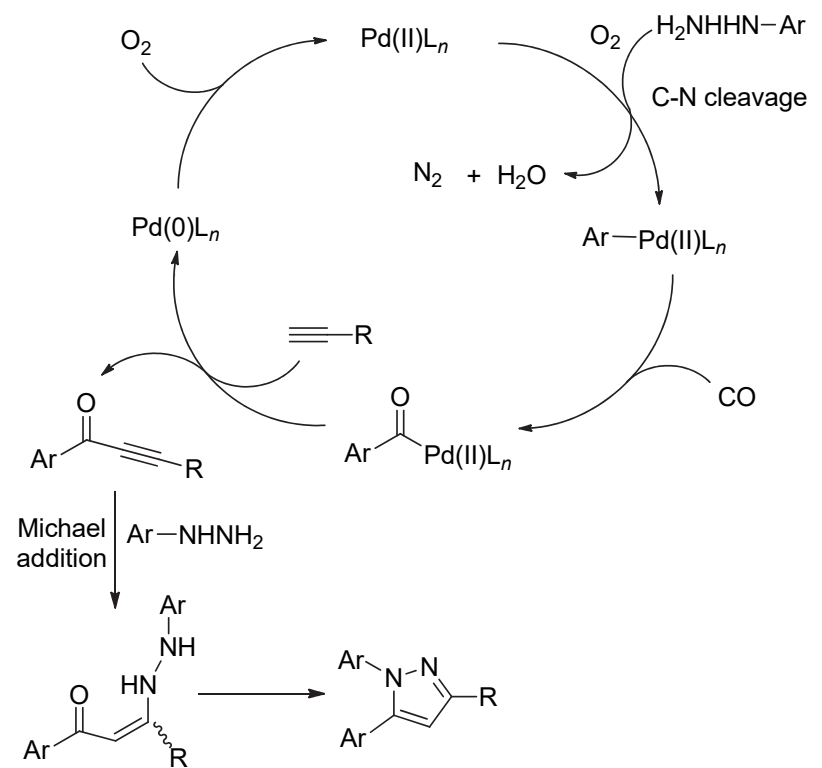

图式 17 串联反应合成三取代吡唑

Scheme 17 Plausible cascade process for synthesis of trisubstituted pyrazole

2015 年, Schmitt 课题组 ${ }^{[56]}$ 使用过渡金属钉催化的 2-烷基-1,3-二醇和肼反应，合成了 1,4 二取代吡唑 85 (Eq. 26). 该方法具有良好的立体选择性，也适用于 $\beta$-着弪 基酮立体选择性的合成不对称的吡唑.

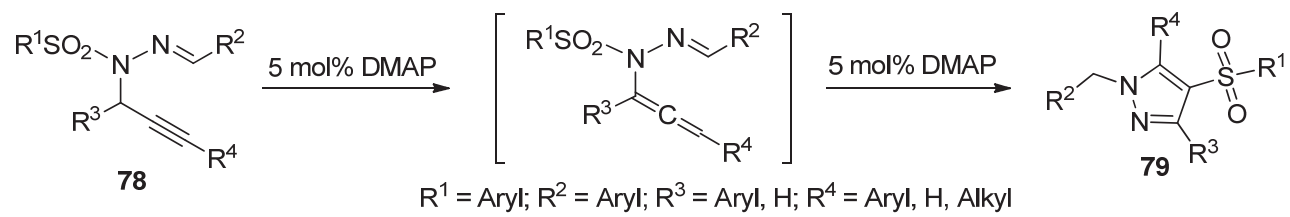

图式 18 炔丙基取代的腙合成吡唑

Scheme 18 Synthesis for pyrazole from propargylpyrenes

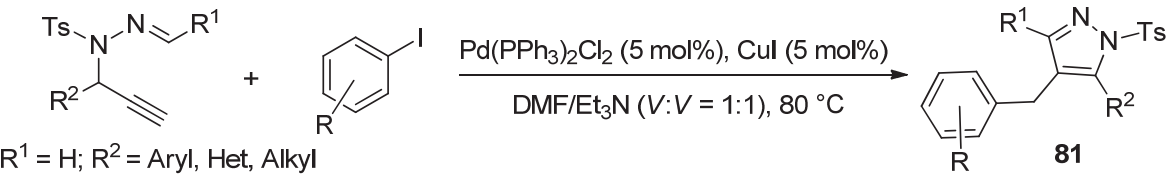

80
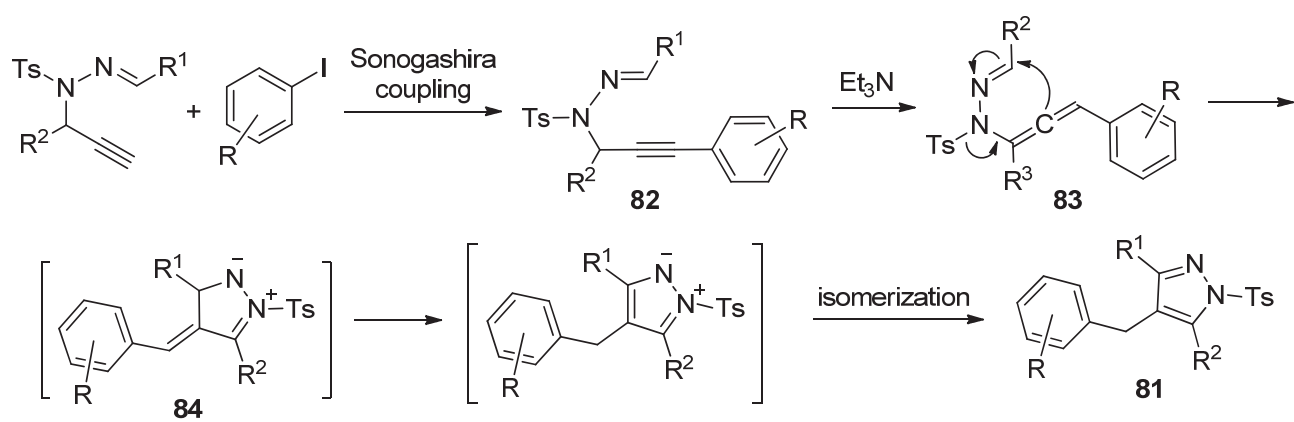

图式 $19 N$-炔丙基磺酰腙合成吡唑反应机理

Scheme 19 Plausible mechanism for the synthesis of pyrazole with $N$-propargyl sulfonylhydrazones 


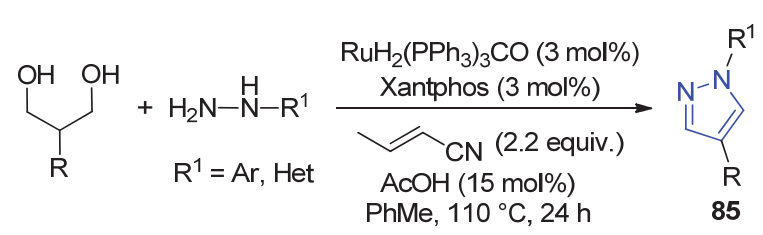

2014 年, 麻生明课题组 ${ }^{[57]}$ 使用铜催化剂, 以联烯 86、胺和取代腈类为反应底物，“一锅法” 合成吡唑类 化合物 87 (Eq. 27).

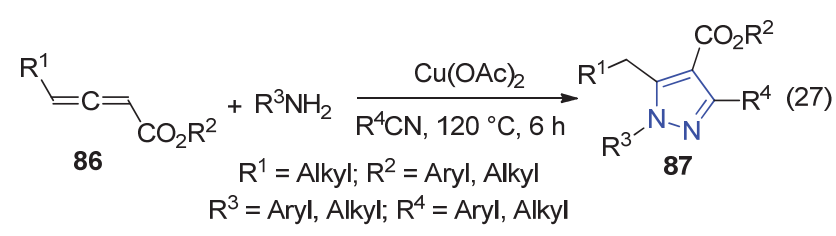

反应的可能机理如 Scheme 20 所示. 联烯 86 和胺进 行 Michael 加成得到中间体 $\mathbf{8 8}$, 然后经过醋酸铜活化的 腈类反应，生成中间体 $\mathbf{8 9}$. 中间体 89 在醋酸铜作用下， 失去两分子醋酸, 得到金属环化的中间体 90, 随后进行 还原消除得到吡唑类化合物. 该反应原料易得、产率高.
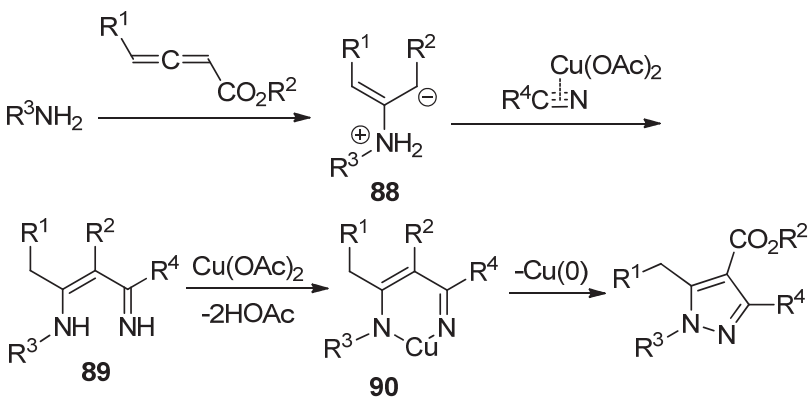

图式 20 联烯、胺和取代腈合成吡唑反应机理 Scheme 20 Plausible mechanism for the synthesis of pyrazole with 2,3-allenoates or 2-alkynoates, amines and nitriles

2014 年, 江焕峰课题组 ${ }^{[58]}$ 在铜催化下, 以肜乙酸盐 91、苯胺和多聚甲醛为底物, DMSO 为溶剂, 加热至 $120{ }^{\circ} \mathrm{C}$ 反应 $12 \mathrm{~h}$, 得到 1,3,4-取代的吡唑 92 (Eq. 28). 该 反应操作简单, 底物适用范围广.

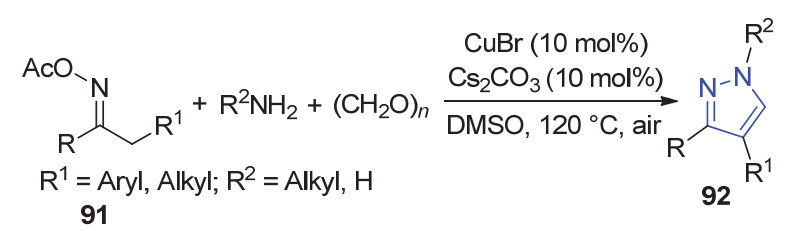

使用离子液体作为反应介质, 可以为溶剂的排放和 催化剂的回收提供解决方案. 离子液体已经成为有机溶 剂和催化剂的优选替代物, 被用作有机反应的反应介质 和催化剂. 为了扩大离子液体 $[\mathrm{DMBSI}] \mathrm{HSO}_{4}$ 在杂环化 合物合成中的应用. 2014 年, Manouchehr 课题组 ${ }^{[59]}$ 使用
$[\mathrm{DMBSI}] \mathrm{HSO}_{4}$ 作催化剂，以 1,3-二羰基化合物、水合肼、 丙二睛、苯甲醛为底物, $60{ }^{\circ} \mathrm{C}$ 条件下，反应 $10 \mathrm{~min}$, 以 95\%的收率得到吡喃并[2,3-c]吡唑 93 (Eq. 29). 该反应 催化剂经过三次连续循环使用，催化剂的活性并没有发 生明显损失.

$$
\text { (29) }
$$

该课题组继续扩大底物醛和腈类化合物的研究的 范围，使用 1,2-二酩化合物为底物，在上述相同的条件 下，以 $85 \% \sim 96 \%$ 的产率得到螺环结构的吡喃并[2,3-c] 吡唑 94 (Eq. 30).
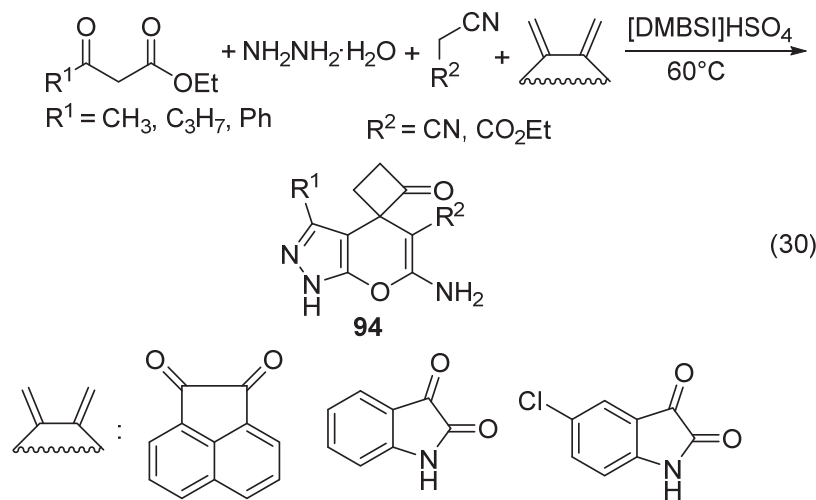<smiles>O=C1Nc2ccc(Cl)cc2C1=O</smiles>

2015 年, Nageswar 课题组 ${ }^{[60]}$ 报道了一种新䵀、温 和、简单高效和绿色合成吡唑衍生物的方法, 即用聚乙 二醇(PEG-400)为反应介质，一锅四组分合成螺 [二氢吲 哚-3,4-吡喃并[2,3-c]吡唑]-3'-羧酸酯衍生物 95 (Eq. 31).

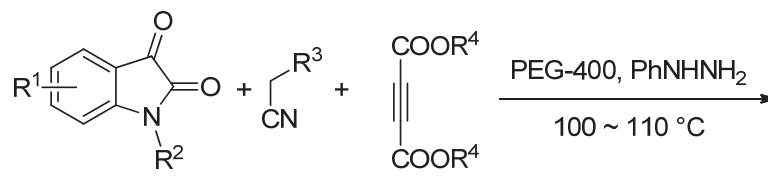
$\mathrm{R}^{1}=\mathrm{CH}_{3}, \mathrm{OCH}_{3}, \mathrm{Cl}, \mathrm{Br}, \mathrm{F} ; \mathrm{R}^{2}=\mathrm{H}, \mathrm{CH}_{3}, \mathrm{Ph}$, Benzyl $\mathrm{R}^{3}=\mathrm{CN}, \mathrm{COOCH}_{3}, \mathrm{COOEt} ; \mathrm{R}^{4}=\mathrm{CH}_{3}$, Et

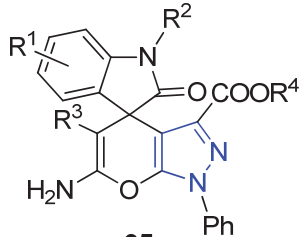


该方法底物范围广谱, 产率高, 易于操作, PEG-400 具 有回收性.

\section{5 结束语}

通过对吡唑及其衍生物合成方法的介绍, 发现其合 成方法众多, 反应的种类也各种各样. 对其总结发现: 第一，自从 Knorr 合成吡唑后，由于其区域选择性不好， 化学家对其不断改进，随后一些区域选择性高、底物适 用范围广的方法被开发. 第二, 腙及其类似物, 叠氮或 者重氮化合物大都经过环化或者环加成反应构建吡唑, 吡唑产物区域选择性高. 腙及其类似物底物容易制备, 但是叠氮或者重氮化合物由于其毒性大、易爆炸，使用 率较低. 第三，近些年光催化、过渡金属催化 $\mathrm{C}-\mathrm{N}$ 、 $\mathrm{N}-\mathrm{N}$ 键构建方法的发展, 也为吡唑的合成提供了一些 新的、简便的方法. 随着人类对于环境保护的重视以及 高效合成的不断追求, 绿色合成将是未来发展方向. 在 化学工作者的不断探索下, 必将进一步简化吡唑类药物 的合成与生产工艺, 助力新的吡唑类功能分子的发现.

\section{References}

[1] (a) Dedeian, K.; Shi, J.; Shepherd, N.; Forsythe, E.; Morton, D. C. Inorg. Chem. 2005, 44, 4445.

(b) Chang, S. Y.; Chen, J. L.; Chi, Y.; Cheng, Y. M.; Lee, G. H.; Jiang, C. M.; Chou, P. T. Inorg. Chem. 2007, 46, 11202.

(c) Cavero, E.; Uriel, S.; Romero, P.; Serrano, J. L.; Giménez, R. J. Am. Chem. Soc. 2007, 129, 11608.

(d) Ye, C.; Gard, G. L.; Winter, R. W.; Syvret, R. G.; Twamley, B.; Shreeve, J. M. Org Lett. 2007, 9, 3841 .

(e) Yang, L.; Okuda, F.; Kobayashi, K.; Nozaki, K.; Tanabe, Y.; Ishii, Y.; Haga, M. Inorg Chem. 2008, 47, 7154.

(f) Seltzman, H. H. Drug Dev. Res. 2009, 70. 601.

(g) Dai, H. X.; Stepan, A. F.; Plummer, M. S.; Zhang, Y. H.; Yu, J. Q. J. Am. Chem. Soc. 2011, 133, 7222.

(h) Jones, L. H.; Allan, G.; Corbau, R.; Middleton, D. S.; Mowbray, C. E.; Newman, S. D.; Phillips, C.; Webster, R.; Westby, M. Chem. Biol. Drug Des. 2011, 77, 393.

(i) Kumar, V.; Kaur, K.; Gupta, G. K.; Sharma, A. K. Eur. J. Med. Chem. 2013, 69, 735 .

[2] (a) Fache, F.; Schulz, E.; Tommasino, M. L.; Lemaire, M. Chem. Rev. 2000, 100, 2159.

(b) Rosiak, A.; Hoenke, C.; Christoffers, J. Eur. J. Org. Chem. 2007, 26, 4376.

(c) Fustero, S.; Sanchez-Rosello, M.; Barrio, P.; Simon-Fuentes, A. Chem. Rev. 2011, 111, 6984.

(d) Hu, J.; Cheng, Y.; Yang, Y.; Rao, Y. Chem. Commun. 2011, 47, 10133.

(e) Lominac, W. J.; D’Angelo, M. L.; Smith, M. D.; Ollison, D. A.; Hanna, J. J. M. Tetrahedron Lett. 2012, 53, 906.

(f) Peng, J.; Xie, Z.; Chen, M.; Wang, J.; Zhu. Q. Org Lett. 2014, 16, 4702 .

(g) Tang, M.; Kong, Y.; Chu, B.; Feng, D. Adv. Synth. Catal. 2016, 358,926 .

[3] Geng, R.; Zhao, Y.; Li, Y.; Liu, X.; Wang, M. Chin. J. Org. Chem. 2019, 39, 3574 (in Chinese)

(耿瑞，赵宇，李益豪，刘釒否磊，王明安，有机化学，2019，39, 3574.)

[4] Zhong, L.; Jiang, T.; Zhang, F.; Fu, Q.; Liu, X.; Xu, T.; Ding, C.; Chen, J.; Yuan, J.; Tan, C. Chin. J. Org. Chem. 2019, 39, 2655 (in
Chinese).

(钟良坤, 江涛, 张帆, 付庆, 刘幸海, 许天明, 丁成荣, 陈杰, 袁静，谭成侠，有机化学, 2019,39, 2655.)

[5] Gong, C. C.; Tan, H. Y.; Zhang, Q. Chin. J. Org. Chem. 2018, 38, 3086 (in Chinese). (龚超超, 谈寒一, 张倩, 有机化学, 2018, 38, 3086.)

[6] He, B.; Wang, D. W.; Yang, W. C.; Chen, Q.; Yang, G. F. Chin. J. Org. Chem. 2017, 37, 2895 (in Chinese).

(何波，王大伟，杨文超，陈琼，杨光富，有机化学，2017，37, 2895.)

[7] Zhong, Y. Y.; Yu, L. J.; He, Q. Y.; Zhu, Q. Y.; Zhang, C. G.; Cui, X P.; Zheng, J. X.; Zhao, S. Q. ACS Appl. Mater. Inter. 2019, 11, 32769 .

[8] Sun, N. B.; Shen, Z. H.; Zhai, Z. W.; Han, L.; Weng, J. Q.; Tan, C. X.; Liu, X. H. Chin. J. Org. Chem. 2017, 37, 2705 (in Chinese). (孙娜波, 沈钟华, 翟志文, 韩亮, 翁建全, 谭成侠, 刘幸海, 有 机化学, 2017, 37, 2705.)

[9] Shi, Y. J.; Zhou, Q.; Wang, Y.; Qian, H. W.; Ye, L. Y.; Feng, X.; Chen, H.; Li, Y. T.; Dai, H.; Wei, Z. H.; Wu, J. M. Chin. J. Org. Chem. 2018, 38, 2450 (in Chinese).

(石玉军, 周钱, 王杨, 钱宏炜, 叶林玉, 冯霞, 陈辉, 李雅婷, 戴红, 魏中昊, 吴锦明, 有机化学, 2018, 38, 2450.)

[10] Zhu, Q.; Yang, Y.; Lao, Z.; Zhong, Y.; Zhang, B.; Cui, X.; O'Neill, P.; Hong, D.; Zhang, K.; Zhao, S. Pest. Manage. Sci. 2019, DOI: 10.1002/ps.5559.

[11] Abd El Razik, H. A.; Badr, M. H.; Atta, A. H.; Mouneir, S. M.; Abu-Serie, M. M. Arch. Pharm. 2017, 350, e1700026.

[12] Schmidt, A.; Dreger, A. Curr. Org. Chem. 2011, 15, 1423.

[13] (a) Bekhit, A. A.; Abdel-Aziem, T. Bioorg. Med. Chem. 2004, 12, 1935.

(b) Selvam, C.; Jachak, S. M.; Thilagavathi, R.; Chakraborti, A. K. Bioorg. Med. Chem. Lett. 2005, 15, 1793.

(c) El-Sayed, M. A. A.; Abdel-Aziz, N. I.; Abdel-Aziz, A. A. M.; El-Azab, A. S.; ElTahir, K. E. H. Bioorg. Med. Chem. 2012, 20, 3306.

[14] Tanitame, A.; Oyamada, Y.; Ofuji, K.; Fujimoto, M.; Iwai, N.; Hiyama, Y.; Suzuki, K.; Ito, H.; Terauchi, H.; Kawasaki, M.; Nagai, K.; Wachi, M.; Yamagishi, J. J. Med. Chem. 2004, 47, 3693.

[15] Bhosle, M. R.; Mali, J. R.; Pal, S.; Srivastava, A. K.; Mane, R. A. Bioorg. Med. Chem. Lett. 2014, 24, 2651.

[16] Penning, T. D.; Talley, J. J.; Bertenshaw, S. R.; Carter, J. S.; Collins, P. W.; Docter, S.; Graneto, M. J.; Lee, L. F.; Malecha, J. W.; Miyashiro, J. M.; Rogers, R. S.; Rogier, D. J.; Yu, S. S.; Anderson, G. D.; Burton, E. G.; Cogburn, J. N.; Gregory, S. A.; Koboldt, C. M.; Perkins, W. E.; Seibert, K.; Veenhuizen, A. W.; Zhang, Y. Y.; Isakson, P. C. J. Med. Chem. 1997, 40, 1347.

[17] Cox, S. R.; Lesman, S. P.; Boucher, J. F.; Krautmann, M. J.; Hummel, B. D.; Savides, M.; Marsh, S.; Fielde, A.; Stegemann, M. R. J. Vet. Pharmacol. Ther. 2010, 33, 461 .

[18] Zhang, D.; Raghavan, N.; Chen, S. Y.; Zhang, H.; Quan, M.; Lecureux, L.; Patrone, L. M.; Lam, P. Y. S.; Bonacorsi, S. J.; Knabb, R. M.; Skiles, G. S.; He, K. Drug Metab. Dispos. 2008, 36, 303.

[19] Lange, J. H. M.; van Stuivenberg, H. H.; Coolen, H. K. A. C.; Adolfs, T. J. P.; McCreary, A. C.; Keizer, H. G.; Wals, H. C.; Veerman, W.; Borst, A. J. M.; de Looff, W.; Verveer, P. C.; Kruse, C. G. J. Med. Chem. 2005, 48, 1823.

[20] Graneto, M. J.; Kurumbail, R. G.; Vazquez, M. L.; Shieh, H. S.; Pawlitz, J. L.; Williams, J. M.; Stallings, W. C.; Geng, L.; Naraian, A. S.; Koszyk, F. J.; Stealey, M. A.; Xu, X. D.; Weier, R. M.; Hanson, G. J.; Mourey, R. J.; Compton, R. P.; Mnich, S. J.; Anderson, G. D.; Monahan, J. B.; Devraj, R. J. Med. Chem. 2007, 50, 5712.

[21] Barth, F.; Rinaldi-Carmona, M. Curr. Med. Chem. 1999, 6, 745.

[22] Cox, B. D.; Prosser, A. R.; Sun, Y.; Li, Z.; Lee, S.; Huang, M. B.; Bond, V. C.; Snyder, J. P.; Krystal, M.; Wilson, L. J.; Liotta, D. C. ACS Med. Chem. Lett. 2015, 6, 753.

[23] Labroli, M. A.; Dwyer, M. P.; Poker, C.; Keertikar, K. M.; Rossman, R.; Guzi, T. J. Tetrahedron Lett. 2016, 57, 2601.

[24] Knorr, L. Ber. Dtsch. Chem. Ges. 1883, 16, 2593. 
[25] Singh, S. P.; Kumar, D.; Batra, H.; Naithani, R.; Rozas, I.; Elguero, J. Can. J. Chem. 2000, 78, 1109.

[26] Oliveira, D. H.; Aquino, T. B.; Nascimento, J. E. R.; Perin, G.; Jacob, R. G.; Alves, D. Adv. Synth. Catal. 2015, 357, 4041.

[27] Zora, M.; Demirci, D.; Kivrak, A.; Kelgokmen, Y. Tetrahedron Lett. 2016, 57, 993.

[28] Sun, P.; Yang, D.; Wei, W.; Sun, X.; Zhang, W.; Zhang, H.; Wang, Y.; Wang, H. Tetrahedron 2017, 73, 2022.

[29] Kalita, S. J.; Bayan, R.; Devi, J.; Brahma, S.; Mecadon, H.; Deka, D. C. Tetrahedron Lett. 2017, 58, 566.

[30] Zhang, H.; Wei, Q.; Zhu, G.; Qu, J.; Wang, B. Tetrahedron Lett. 2016, 57, 2633.

[31] Markovic, V.; Joksovic, M. D. Green Chem. 2015, 17, 842.

[32] Vekariya, R. H.; Patel, K. D.; Patel, H. D. Res. Chem. Intermed. 2016, 42, 4683.

[33] Saha, A.; Payra, S.; Banerjee, S. Green Chem. 2015, 17, 2859.

[34] Sun, A.; Ye, J. H.; Yu, H.; Zhang, W.; Wang, X. Tetrahedron Lett. 2014, 55, 889.

[35] Kong, Y.; Tang, M.; Wang, Y. Org. Lett. 2014, 16, 576.

[36] Tang, M.; Wang, Y.; Wang, H.; Kong, Y. Synthesis 2016, 48, 3065.

[37] Senadi, G. C.; Hu, W. P.; Lu, T. Y.; Garkhedkar, A. M.; Vandavasi, J. K.; Wang, J. J. Org Lett. 2015, 17, 1521.

[38] Alizadeh, A.; Moafi, L.; Zhu, L. G. Synlett 2016, 27, 595.

[39] Shi, C.; Ma, C.; Ma, H.; Zhou, X.; Cao, J.; Fan, Y.; Huang, G. Tetrahedron 2016, 72, 4055.

[40] Yu, Y.; Huang, W.; Chen, Y.; Gao, B.; Wu, W.; Jiang, H. Green Chem. 2016, 18, 6445.

[41] Mukherjee, S.; Kundu, A.; Pramanik, A. Tetrahedron Lett. 2016, 57, 2103.

[42] Zhang, G.; Ni, H.; Chen, W.; Shao, J.; Liu, H.; Chen, B.; Yu, Y. Org. Lett. 2013, 15, 5967.

[43] Zhang, J.; Chen, W.; Huang, D.; Zeng, X.; Wang, X.; Hu, Y. Tetrahedron Lett. 2017, 58, 4133.

[44] Kumar, R.; Nair, D.; Namboothiri, I. N. N. Tetrahedron 2014, 70, 179.
[45] Nair, D.; Pavashe, P.; Katiyar, S.; Namboothiri, I. N. N. Tetrahedron Lett. 2016, 57, 3146.

[46] Ahamad, S.; Gupta, A. K.; Kant, R.; Mohanan, K. Org. Biomol. Chem. 2015, 13, 1492.

[47] Shao, Y.; Tong, J.; Zhao, Y.; Zheng, H.; Ma, L.; Ma, M.; Wan, X. Org. Biomol. Chem. 2016, 14, 8486.

[48] (a) Yuan, B.; Zhang, F.; Li, Z.; Yang, S.; Yan, R. Org. Lett. 2016, $18,5928$.

(b) Unnava, R.; Saikia A. K. ChemistrySlect 2016, 1, 1816.

[49] Yadav, S.; Rai, P.; Srivastava, M.; Singh, J.; Tiwari, K. P.; Singh, J. Tetrahedron Lett. 2015, 56, 5831.

[50] Cheng, J.; Li, W.; Duan, Y.; Cheng, Y.; Yu, S.; Zhu, C. Org. Lett. 2017, 19, 214.

[51] Dhage, Y. D.; Daimon, H.; Peng, C.; Kusakabe, T.; Takahashi, K.; Kanno, Y.; Inouye, Y.; Kato, K. Org. Biomol. Chem. 2014, 12, 8619.

[52] Li, D. Y.; Mao, X. F.; Chen, H. J.; Chen, G. R.; Liu, P. N. Org. Lett. 2014, 16, 3476.

[53] Tu, Y.; Zhang, Z.; Wang, T.; Ke, J.; Zhao, J. Org. Lett. 2017, 19, 3466.

[54] Zhu, Y.; Lu, W. T.; Sun, H. C.; Zhan, Z. P. Org. Lett. 2013, 15, 4146.

[55] Yang, Y.; Hu, Z. L.; Li, R. H.; Chen, Y. H.; Zhan, Z. P. Org. Biomol. Chem. 2018, 16, 197.

[56] Schmitt, D. C.; Taylor, A. P.; Flick, A. C.; Kyne, R. E. Org. Lett. 2015, 17, 1405.

[57] Chen, B.; Zhu, C.; Tang, Y.; Ma, S. Chem. Commun. 2014, 50, 7677.

[58] Tang, X.; Huang, L.; Yang, J.; Xu, Y.; Wu, W.; Jiang, H. Chem. Commun. 2014, 50, 14793.

[59] Mamaghani, M.; Hossein, R.; Shirini, F.; Tabatabaeian, K.; Rassa, M. Med. Chem. Res. 2015, 24, 1916.

[60] Karnakar, K.; Ramesh, K.; Reddy, K. H. V.; Anil Kumar, B. S. P.; Nanubonula, J. B.; Nageswar, Y. V. D. New J. Chem. 2015, 39, 8978.

(Cheng, F.) 